\title{
Matrix metalloproteinase-1 as a non-invasive biomarker to assess liver fibrosis in children with chronic liver disease
}

\author{
Ola Galal Behairy ${ }^{1 *} \mathbb{D}$, Mohamed Mostafa El-Bakry ${ }^{1}$, Amira Ibrahim Mansour², Amira M. N. Abdelrahman² and \\ Ghada Mansour Emam³
}

\begin{abstract}
Background: Abnormal extracellular matrix (ECM) turnover is linked to liver fibrosis as it reflects an imbalance between repair and progressive substitution of the liver parenchyma by scar tissue. Matrix metalloproteinases (MMPs) are the primary enzymes involved in ECM breakdown. So, this study aims to measure the value of serum matrix metalloproteinase-1 (MMP-1) in children with chronic liver diseases (CLD) in comparison with liver biopsy and serum biomarkers. A hundred twenty children with chronic liver diseases and sixty healthy children as a control group were included in this study. Both groups were evaluated via medical history, clinical, radiological, laboratory investigations, and serum MMP-1 level was measured by ELISA. Liver biopsy was performed for studied patients only.
\end{abstract}

Results: The mean MMP-1 was $15.2 \pm 5.1 \mathrm{ng} / \mathrm{ml}$ in children with CLD, and $64.7 \pm 27.4 \mathrm{ng} / \mathrm{ml}$ in the control group. MMP-1 was statistically lower in the children with CLD than controls $(p<0.001)$. The mean \pm SD of aspartate aminotransferase to platelet ratio index (APRI) and fibrosis-4 (FIB-4) scores in all studied cases showed a significant trend of increase with progressive fibrosis stage evident with histological METAVIR scoring system, while serum MMP-1 concentration was decreased significantly with increasing the degree of fibrosis in CLD group (P 0.001). Serum MMP-1 was indirectly correlated with serum biomarkers and the degree of fibrosis in patients.

Conclusions: MMP-1 is a useful non-invasive marker for detection of the stage of liver fibrosis in children with chronic liver diseases.

Keywords: MMP-1, Chronic liver disease, Liver fibrosis, Children

\section{Background}

Chronic liver diseases (CLD) are arising health issues in children with significant morbidity and mortality [1]. CLD encompasses a broad range of disorders characterized by chronic liver damage with the potential to progress to cirrhosis or end-stage liver disease [2]. Several pediatric liver disorders are known to be precursors of adult chronic hepatitis [3].

\footnotetext{
*Correspondence: olaped99@yahoo.com; ola.behery@fmed.bu.edu.eg ${ }^{1}$ Pediatrics Department, Faculty of Medicine, Benha University, Qualiopia, Benha, Egypt

Full list of author information is available at the end of the article
}

After chronic liver injury, a sequence of pathological and physiological processes linked to liver cell necrosis and degeneration, which finally result in extracellular matrix and collagen deposition resulting in liver fibrosis [4]. Injured hepatocytes release proinflammatory factors, which attract and trigger immune cells that activate dominant hepatic stellate cells (HSCs) just as they do during hepatic damage. HSCs become highly proliferative, migratory, contractile and extracellular matrix (ECM)-producing myofibroblasts after activation. Fibrosis is the formation of scar tissue caused by a disruption in the equilibrium between ECM deposition and degradation. This balance can be restored 
by either decreasing ECM deposition (by inhibiting HSCs activation and proliferation) or increasing ECM degradation (by increasing matrix metalloproteinases expression) [5].

The biopsy is widely recognized as the gold standard for diagnosing and staging liver fibrosis. This approach, however, has some drawbacks, including the possibility of sampling variability, pain, and low-patient acceptance. Furthermore, it is still debatable whether a tissue diagnosis of liver fibrosis is needed. In cases of viral hepatitis, there are now an increasing number of effective noninvasive approaches that are widely used in clinical practice, resulting in a substantial reduction in the need for liver biopsy [4].

MMP-1, also known as collagenase-1, is a protein that cleaves both ECM and non-ECM substrates including collagen, gelatin, laminin, complement $\mathrm{C} 1 \mathrm{q}$, interleukin 1 beta, and tumor necrosis factor-alpha and thus plays a role in fibrotic and inflammatory processes [6]. It has been reported that MMP-1 overexpression attenuates fibrosis by promoting collagenase- 1 degradation, alters the ECM network and thereby the cell-ECM interaction, induces hepatocyte proliferation and thus liver regeneration, and promotes HSC apoptosis and hence reduced collagen production [7]. MMP-1 also plays a crucial role in ECM degradation during the recovery phase of experimental liver fibrosis [8].

Therefore, we conducted this study aiming to measure the value of serum MMP-1 in children with CLD in comparison with liver biopsy and serum biomarkers.

\section{Methods}

\section{Study design and population}

This cross-sectional comparative study was conducted on 180 children, who were divided into two groups: children with CLD group included 120 children diagnosed with a long-term permanent alternation in the hepatic structure that can lead to complications including cirrhosis and premature death [9] based on clinical, laboratory, and histopathological examinations. Patients were recruited from the pediatric hepatology outpatient clinic of Benha University Hospitals between December 2018 and December 2020, along with $60 \mathrm{age} / \mathrm{sex}$-matched healthy children as the control group. Control subjects were children who went to an outpatient clinic for a regular checkup for athletic training or school routine examination. Patients with CLD of different etiologies (chronic viral hepatitis B or/and $\mathrm{C}$, cholestatic liver disease, autoimmune hepatitis, or metabolic liver diseases) were included. Any CLD patient with comorbidity (renal, CVS, or CNS affection) was excluded. The study was approved by the Ethical Committee of Faculty of Medicine, Benha
University following "The Code of Ethics of the World Medical Association" (Declaration of Helsinki). Consent was obtained from parents/guardians after being fully informed about all study procedures before enrolment.

* All of the children who were enrolled underwent a complete history taking and clinical examination with a focus on clinical presentations (jaundice, abdominal pain and distension, melena and bleeding manifestations such as hematuria, epistaxis, or bleeding gums), abdominal ultrasonography and laboratory investigations including the following:

- Complete blood picture by Sysmex-XP300 [10], prothrombin time (PT), and activated partial thromboplastin time (aPTT) were done by TEClot PT-S on Coatron A4 instrument (Germany) [11], and liver function tests; aspartate aminotransferase (AST), alanine aminotransferase (ALT), alkaline phosphatase (ALP), gamma-glutamyl transpeptidase (GGT), and total and direct bilirubin and serum albumin were done by Biosystem A1A-auto analyser-Spain [12].

- Serum immunoglobulin G (IgG): By radial immunodiffusion using (IgG-NLRID, RN004.3, Binding Site, Birmingham, UK) [13].

- Serum autoantibodies which include anti-nuclear antibodies (ANA), anti-smooth muscle antibodies (ASMA), liver-kidney microsome antibodies (anti-LKM-1), anti-liver cytosol type 1 (LC1), and anti-mitochondrial antibodies (AMA) titer were performed by indirect immunofluorescence technique using NOVA Lite Rat Liver, Kidney, Stomach (INOVA Diagnostic Inc., Germany) [14].

- Serological tests for viral hepatitis B and C: Hepatitis $\mathrm{B}$ surface antigen ( $\mathrm{HBs} \mathrm{Ag}$ ), and anti-HCV antibody (HCV-Ab) by enzyme-linked immunosorbent assay (ELISA) third generation, using the kit from Abbott laboratories (Wiesbaden, Delknheim, Germany) [15] and confirmation was done by using PCR (Biokit, Spain) [16]

- Work-up for Wilson's disease (serum ceruloplasmin, 24-h urinary copper before and after penicillamine) and slit-lamp examination for Keyser-Fleischer ring [12]

- Work-up for Tyrosenemia by succinylacetone in serum and urine, alpha-fetoprotein, and urine analysis for detection of multiple urinary losses [12]

- Work-up for Neiman pick by (bone marrow aspiration and fundus examination) [17]

- Serum MMP-1 levels were measured using human enzyme-linked immunosorbent assay (ELISA) (sandwich technique) kits provided by Human Matrix 
Metalloproteinase-1 ELISA Kit (Bioassay Technology Laboratory) (Ct. No. E0916Hu) [18, 19].

- Additional surrogate blood indices of liver fibrosis were calculated according to the published analytic recommendations $[20,21]$ as follows:

- Aspartate aminotransferase to platelet ratio index (APRI), the APRI were calculated as follows: APRI = ((AST/upper limit of a normal range of AST) $\times 100) /$ platelet count $\left(10^{9} / \mathrm{L}\right)$.

- Fibrosis-4 (FIB-4) $=[$ age $($ years $) \times$ AST $(\mathrm{IU} / \mathrm{L})] /$ [platelets count $\left(10^{9} / \mathrm{L}\right) \times \sqrt{ }$ ALT $\left.(\mathrm{IU} / \mathrm{L})\right]$.

All patients had an ultrasound-guided liver biopsy using the Menghini aspiration needle to obtain sufficient core containing at least 11 portal tracts (Hepafix Luer Lock Braun Melsungen AG, Melsungen, Germany). Formalin-fixed, paraffin-embedded biopsy specimens were cut and stained with hematoxylin and eosin to assess the histological activity of liver disease using the METAVIR scoring system [22], which comprises five stages: F0 (no fibrosis), F1 (minimal fibrosis, portal fibrosis without septa), F2 (moderate fibrosis, portal fibrosis with few septa), F3 (severe fibrosis, septal fibrosis with many septa but no cirrhosis), and F4 (cirrhosis). Activity (based on the intensity of macro-inflammatory activity, interface hepatitis, and lobulitis) was graded as follows: $\mathrm{A} 0=$ no histological activity, $\mathrm{A} 1=$ mild activity, $\mathrm{A} 2=$ moderate activity, A3 = severe activity [22]. Sections were stained with Mason-Trichrome to assess fibrosis stage, Perls' Prussian blue stain to show iron deposition, and periodic acid chief stain to exclude alpha 1 anti-trypsin deficiency. Two pathologists blindly evaluated the slides.

\section{Statistical methods}

The collected data were tabulated and analyzed using the SPSS software, v. 16 (SPSS Inc., Chicago, IL, USA). Qualitative data were described as number (percent) and the chi-square $\left(x^{2}\right)$ test was used to compare between them. Quantitative data were described as mean \pm standard deviation (SD). Student $(t)$ and ANOVA $(F)$ tests were used to compare between two or more groups respectively. Pearson's correlation coefficient $(r)$ was used to assess correlations between variables. ROC curve analysis was used to detect cut-off values of serum MMP1with optimum sensitivity and specificity in the diagnosis of early and advanced fibrosis. Multivariate analysis was performed to predict fibrosis score. The significance of the obtained results was accepted at $P$ value 0.05 with $95 \%$ confidence interval $(P<0.05$ was considered significant).

\section{Results}

This study included 120 CLD children of different etiologies; they were 70 males and 50 females with a mean age of $11.1 \pm 5.3$ years ranged from 2 years to 17 years. While the 60 healthy control children were 29 males and 31 females with a mean age of $10.3 \pm 4.4$ years ranged from 2 years to 17 years. Both groups were sex and agematched $(P=0.320,0.212$ respectively).

\section{Etiology and clinical presentation of CLD in the patient group}

The diagnosis of the studied CLD patients was achieved via comprehensive investigations and the underlying etiologies were verified with liver biopsies which also determined the exact fibrosis stage in each case

Table 1 Distribution of histopathological fibrosis stages according to different etiologies of chronic liver diseases

\begin{tabular}{|c|c|c|c|c|c|}
\hline \multirow[t]{3}{*}{ Diagnosis } & & \multicolumn{4}{|c|}{ Fibrosis stage } \\
\hline & & \multirow{2}{*}{$\begin{array}{l}\mathrm{F} 1 \\
N=67\end{array}$} & \multirow{2}{*}{$\begin{array}{l}\mathrm{F} 2 \\
N=27\end{array}$} & \multirow{2}{*}{$\begin{array}{l}\mathrm{F} 3 \\
N=10\end{array}$} & \multirow{2}{*}{$\begin{array}{l}\mathrm{F} 4 \\
N=16\end{array}$} \\
\hline & & & & & \\
\hline Autoimmune hepatitis (29) & & 25 & 4 & 0 & 0 \\
\hline \multirow[t]{2}{*}{ Cholestasis } & Biliary atresia $(n=14)$ & 2 & 6 & 4 & 2 \\
\hline & Familial intrahepatic cholestasis $(n=3)$ & 0 & 3 & 0 & 0 \\
\hline \multirow[t]{2}{*}{ Viral hepatitis } & $\operatorname{HBV}(n=5)$ & 4 & 1 & 0 & 0 \\
\hline & $\operatorname{HCV}(n=18)$ & 15 & 3 & 0 & 0 \\
\hline Congenital hepatic fibrosis $(n=9)$ & & 3 & 3 & 3 & 0 \\
\hline \multirow[t]{4}{*}{ Metabolic liver diseases } & Glycogen storage disease $(n=21)$ & 16 & 5 & 0 & 0 \\
\hline & Wilson disease $(n=5)$ & 0 & 0 & 2 & 3 \\
\hline & Tyrosenemia $(n=2)$ & 0 & 0 & 0 & 2 \\
\hline & Neiman pick $(n=3)$ & 0 & 0 & 0 & 3 \\
\hline \multicolumn{2}{|c|}{ Chronic hepatitis for differential diagnosis $(n=11)$} & 2 & 2 & 1 & 6 \\
\hline
\end{tabular}


(Table 1). The underlying etiologies of CLD in the studied patients were genetic-metabolic disorders [glycogen storage disease (21 case) (17.5\%) [GSD-I (12 cases), GSD-II (4 cases), GSD-III (5 cases)], Niemen Pick disease (3 cases) (type A ( 2 cases) and type B (1case)) (2.5\%), Wilson disease (5 cases) (4.1\%), and tyrosinemia 2 cases (1.7\%)], autoimmune hepatitis type-I (29 cases) (24.2\%), congenital hepatic fibrosis (9 cases) (7.5\%), chronic hepatitis for differential diagnosis (11 cases) (9.2\%), infective hepatitis (HBV) (5 cases) (4.10\%) and HCV (18 cases) (15\%), and cholestatic liver disease (biliary atresia) (14 cases) (11.7\%), familial intrahepatic cholestasis (PFIC-1) (3 cases) (2.5\%).

Clinical presentation of CLD patients were jaundice (48.3\%), abdominal distention (19.2\%), clay color stool (11.7\%), abdominal pain (5\%), faltering of growth $(5.7 \%)$, convulsion $(4.2 \%)$, and pallor $(4.2 \%)$. Abdominal ultrasonography revealed that $80 \%$ of patients had hepatomegaly and $33 \%$ had splenomegaly.

\section{Laboratory characteristics and histopathological evaluation of the studied subjects}

Baseline laboratory data of studied subjects showed that there was statistically significant difference between CLD patients and healthy controls regarding liver function tests (ALT, AST, PT, albumin, bilirubin) as they were higher in CLD patients (Table 2).

Histopathological evaluation of liver biopsy according to the METAVIR scoring [22] revealed that disease activity was mild (A1) in $51.7 \%$, moderate (A2) in $25.8 \%$, and severe (A3) in $22.5 \%$. Meanwhile, degree of fibrosis $(55.8 \%$ ) had minimal fibrosis (F1), $22.5 \%$ had moderate fibrosis (F2), 8.3\% had severe fibrosis (F3), and $13.3 \%$ had cirrhosis (F4).

Table 2 Laboratory data of the studied groups

\begin{tabular}{llll}
\hline Variables & $\begin{array}{l}\text { CLD patients } \\
\mathbf{N}=\mathbf{1 2 0}\end{array}$ & $\begin{array}{l}\text { Healthy controls } \\
\mathbf{N}=\mathbf{6 0}\end{array}$ & $\begin{array}{l}\boldsymbol{P} \text { value } \\
\end{array}$ \\
\hline ALT (IU/L) median (IQR) & $50(45-101)$ & $10(9-11)^{\mathrm{a}}$ & $<0.001$ \\
AST (IU/L) median (IQR) & $72(56-95)$ & $11(10-11)^{\mathrm{a}}$ & $<0.001$ \\
PT (s) & $14.7 \pm 3.7$ & $12.7 \pm 1^{\mathrm{b}}$ & $<0.001$ \\
Albumin (g/L) & $3.37 \pm 0.4$ & $3.66 \pm 0.19^{\mathrm{b}}$ & 0.09 \\
Bilirubin total (mg/dL) & $4.5 \pm 0.8$ & $1.1 \pm 0.19^{\mathrm{b}}$ & $<0.001$ \\
Bilirubin direct (mg/dL) & $2.77 \pm 0.94$ & $0.66 \pm 0.19^{\mathrm{b}}$ & $<0.001$ \\
MMP-1 ng/ml & 17.5 & $67.6^{\mathrm{a}}$ & $<0.001$ \\
Median (IQR) & $16.5-18.4$ & $55-83$ & \\
\hline
\end{tabular}

a $U$ Man-Whitney test

${ }^{\mathrm{b}} t$ test, $H b$ hemoglobin, WBCs white blood cells, PLT platelets, ALT alanine aminotransferase, AST aspartate aminotransferase, PT prothrombin time, MMP-1 matrix metalloproteinases-1
Non-invasive biomarkers for assessment of hepatic fibrosis Applying the non-invasive surrogate blood indices of liver fibrosis revealed that the mean \pm SD of APRI and FIB- 4 scores ( $1.1 \pm 0.85$ and $0.53 \pm 0.54$ respectively) in all studied cases and they showed a significant trend of increase with increasing the degree of fibrosis stage evident with histological METAVIR scoring system $(P 0.001)$ (Table 3).

\section{Serum matrix metalloproteinase- 1 assessment}

Serum matrix metalloproteinases-1 (MMP-1) level was significantly lower in CLD patients compared to healthy controls $(P<0.001)$ (Table 2).

Serum MMP-1 concentration was decreased significantly with increasing the degree of fibrosis in CLD patients (Table 3).

Serum MMP-1 level did not differ according to CLD etiologies in studied patients $(P>0.05)$ (Table 4$)$.

Serum MMP-1 was found to be negatively correlated with AST $(r=-0.448, P<0.001)$, ALT $(r=-0.389, P<$ $0.001)$, GGT $(r=-0.544, P<0.001)$, ALP $(r=-0.675, P$ $<0.001)$, PT $(r=-0.361, \mathrm{P}<0.001)$, degree of fibrosis $(r$ $=-0.960, P<0.001)$, (APRI) $(r=-0.653, P<0.001)$, and FIB-4 $(r=-0.557, P<0.009)$ and positively correlated with serum albumin $(r=0.312, P<0.001)$, hemoglobin level $(r=0.327, P<0.001)$, and platelets count $(r=0.446$, $P<0.001)$.

\section{Diagnostic performance and predictive value of serum MMP-1, APRI, and FIB-4}

The diagnostic performances of studied biomarkers to detect the presence of fibrosis (> F0) in children with CLD indicated that serum MMP-1 at a cut-off value $\leq 21.3 \mathrm{ng} / \mathrm{ml}$ had a $95 \%$ sensitivity, $95 \%$ specificity with a fair area under the ROC curve (AUC) of 0.972 (95\% confidence interval, 0.909-0.987), $p<0.001$, while APRI at cut-off index $\geq 0.35$ had a $95.8 \%$ sensitivity,

Table 3 Comparison between the histopathological degree of fibrosis and non-invasive fibrosis scores (APRI and FIB-4) and serum MMP-1 level in chronic liver disease patients

\begin{tabular}{llll}
\hline Degree of fibrosis & APRI & FIB-4 & MMP-1 (nglml) \\
\hline F1 $(n=67)$ & $0.70 \pm 0.5$ & $0.26 \pm 0.13$ & $19.2 \pm 1.5$ \\
F2 $(n=27)$ & $0.74 \pm 0.59$ & $0.33 \pm 0.19$ & $13.1 \pm 0.7$ \\
F3 $(n=10)$ & $2.3 \pm 0.38$ & $0.85 \pm 0.54$ & $8.8 \pm 0.4$ \\
F4 $(n=16)$ & $2.55 \pm 0.02$ & $2.01 \pm 0.04$ & $6.2 \pm 0.5$ \\
F value & 74.5 & 164.7 & 24.5 \\
P & 0.001 & 0.001 & 0.001 \\
\hline
\end{tabular}

Data represented as mean $\pm \mathrm{SD}$

Fone-way ANOVA, APRI aspartate aminotransferase to platelet ratio index, FIB-4 fibrosis-4 index, $F F$ value in ANOVA test 
Table 4 Comparison between levels of MMP-1 as regard to diagnosis of the CLD group

\begin{tabular}{|c|c|c|c|c|c|}
\hline \multirow[t]{2}{*}{ Diagnosis } & & \multicolumn{2}{|c|}{ MMP-1 ng/ml } & \multirow[t]{2}{*}{ Test } & \multirow[t]{2}{*}{$P$ value } \\
\hline & & Mean \pm SD & Range & & \\
\hline \multicolumn{2}{|l|}{ Autoimmune hepatitis } & $15.1 \pm 1.9$ & $11.5-21.5$ & $F=2.6$ & 0.071 \\
\hline \multirow[t]{2}{*}{ Cholestasis } & Biliary atresia & $12.7 \pm 3.4$ & $6-18.5$ & & \\
\hline & Familial intrahepatic cholestasis & $13.3 \pm 2.3$ & $8-15.5$ & & \\
\hline \multirow[t]{2}{*}{ Viral hepatitis } & HBV & $14.7 \pm 2.6$ & $12.5-17$ & & \\
\hline & HCV & $15.9 \pm 1.6$ & $15.5-19$ & & \\
\hline \multicolumn{2}{|l|}{ Congenital hepatic fibrosis } & $14.5 \pm 2.8$ & $9.1-16$ & & \\
\hline \multirow[t]{4}{*}{ Metabolic liver diseases } & Glycogen storage disease & $16.6 \pm 3.9$ & $12-20.5$ & & \\
\hline & Wilson disease & $13.4 \pm 3.9$ & 7.1-19 & & \\
\hline & Tyrosinemia & $14.3 \pm 1.6$ & $5-19$ & & \\
\hline & Neiman pick & $12.5 \pm 1.5$ & $8.5-15$ & & \\
\hline \multicolumn{2}{|c|}{ Chronic hepatitis for differential diagnosis } & $16.1 \pm 5.5$ & $6-19.5$ & & \\
\hline
\end{tabular}

$H B V$ hepatitis $B$ virus, $H C V$ hepatitis $C$ virus, F one-way ANOVA, MMP matrix metalloproteinase

$100 \%$ specificity with a fair AUC of 0.965 (95\% confidence interval, 0.934-0.995), $p<0.001$. For FIB-4, at a cut-off index $\geq 0.11$, it had a $90.1 \%$ sensitivity, $100 \%$ specificity with AUC of 0.978 (95\% confidence interval, 0.940-0.994), $p<0.001$ (Fig. 1).

While at cut-off value $\leq 10.5 \mathrm{ng} / \mathrm{ml}$ with $100 \%$ sensitivity, $100 \%$ specificity, with excellent AUC of 1 (95\% confidence interval, $1-1), p<0.001$ serum MMP-1 could detect severe fibrosis ( $\geq$ F3 METAVIR). While, APRI could detect severe fibrosis $(\geq$ F3 METAVIR) at cut-off index $\geq 1.44$, with sensitivity $100 \%$, specificity $89.7 \%$, with a good AUC of 0.975 (95\% confidence interval, 0.952-0.998), $p<$ 0.001 . Also, FIB- 4 at cut-off value $\geq 0.44$ with $100 \%$ sensitivity, $75.6 \%$ specificity, with a good AUC of 0.939 (95\% confidence interval, 0.890-0.981), $p<$ 0.001 could detect severe fibrosis ( $\geq$ F3 METAVIR) in children with CLD (Fig. 2).

Multiple linear regression analysis revealed that platelet, AST, ALT, PT, APRI, FIB-4, and MMP-1 are potential predictors for detecting fibrosis in children with CLD (Table 5).

\section{Discussion}

Extracellular matrix-related pathways have been linked to both liver damage and regeneration. Although normal ECM depletion is an essential part of tissue repair and remodeling, abnormal ECM turnover is linked to several

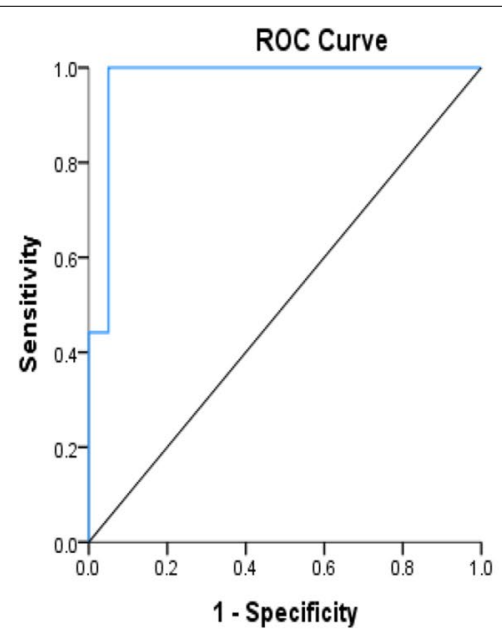

A

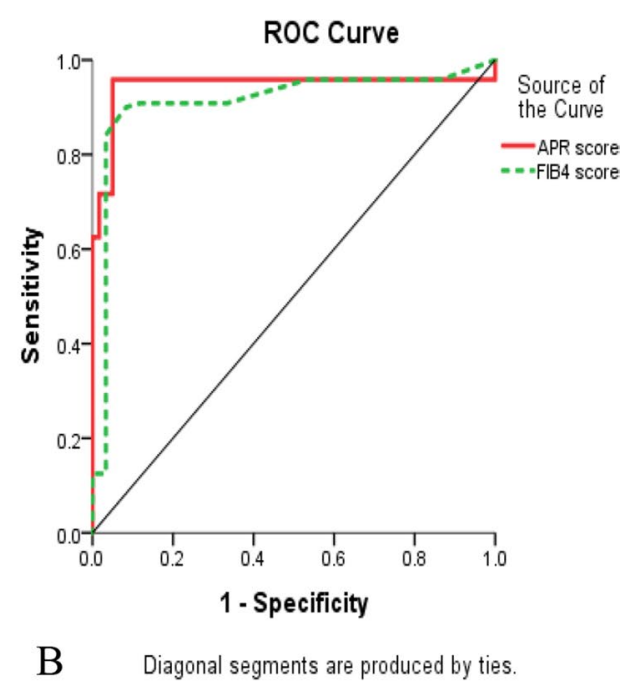

Fig. 1 A Receiver operating characteristic (ROC) curve for the diagnostic performance for detection of the presence of fibrosis in children with chronic liver disease from control for MMP-1. B Receiver operating characteristic (ROC) curve for the diagnostic performance of APRI and FIB-4 for detection of the presence of fibrosis in children with chronic liver disease 


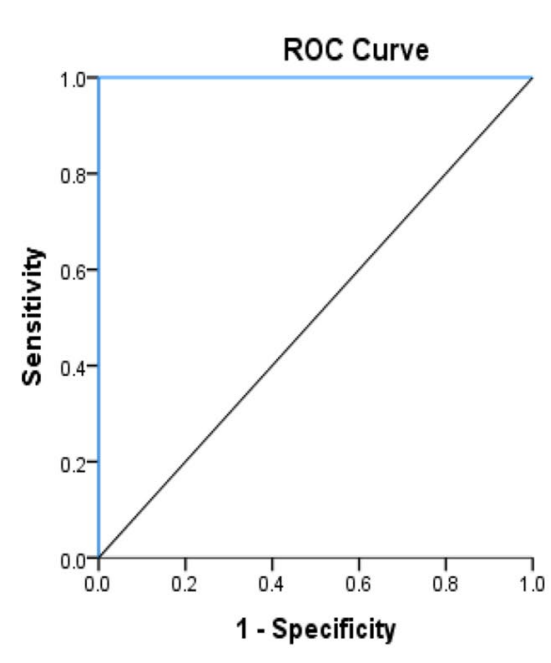

A

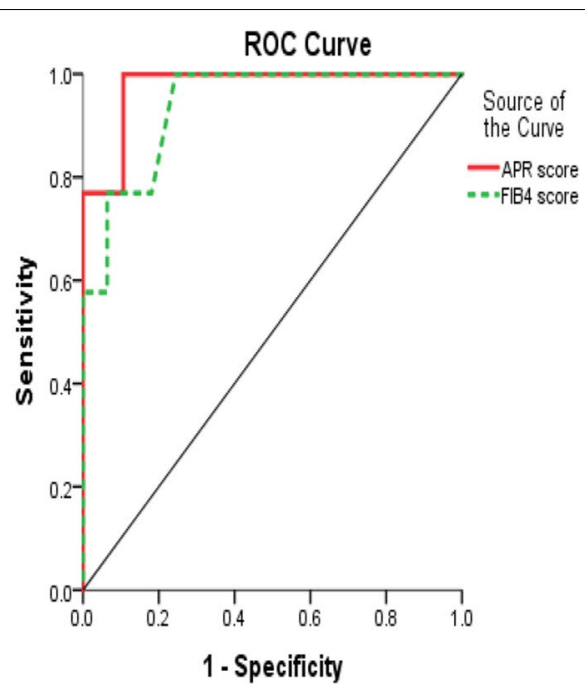

B Diagonal segments are produced by ties.

Fig. 2 A Receiver operating characteristic (ROC) curve for the diagnostic performance of for prediction of F3 \& F4 in CLD group for MMP-1. B Receiver operating characteristic (ROC) curve for the diagnostic performance of for prediction of F3 and F4 in CLD group for APRI and FIB-4

liver diseases. The key enzymes involved in ECM degradation are matrix metalloproteinases (MMPs). MMPs are involved in not only remodeling of the ECM but also the regulation of immune responses [23]. In the present study, the most frequent diagnosis was metabolic liver diseases followed by autoimmune hepatitis, infectious hepatitis, cholestasis, congenital hepatic fibrosis, and chronic hepatitis for differential diagnosis. These results were comparable with previous studies $[1,24]$, as the etiological spectrum of CLD varies according to patients' age, geographical location of the study, prevalence of the disease, availability of diagnostic tools, experience of the physicians, and referral pattern [25].

In the current study, the mean MMP-1 was statistically lower in the CLD group than in controls. This was in line with a previous study in which MMP-1 serum levels were

Table 5 Multiple linear regression analysis for predictors of fibrosis

\begin{tabular}{|c|c|c|c|c|}
\hline & \multirow[t]{2}{*}{$\beta$} & \multicolumn{2}{|l|}{$95 \% \mathrm{Cl}$} & \multirow[t]{2}{*}{$P$ value } \\
\hline & & Lower & Upper & \\
\hline Platelet $\left(10^{3} / \mathrm{l}\right)$ & -0.002 & -0.002 & -.001 & $<0.001$ \\
\hline ALT (IU/L) & 0.502 & 0.301 & 0.604 & 0.01 \\
\hline AST (IU/L) & 0.402 & 0.204 & 0.501 & 0.02 \\
\hline PT (s) & 0.106 & 0.059 & 0.154 & $<0.001$ \\
\hline MMP-1 (ng/ml) & -0.074 & -0.096 & -0.053 & $<0.001$ \\
\hline APRI score & 0.458 & 0.264 & 0.651 & $<0.001$ \\
\hline FIB-4 score & -0.287 & -0.550 & -0.023 & 0.033 \\
\hline
\end{tabular}

$\beta$ estimated regression coefficient, $A L T$ alanine aminotransferase, AST aspartate aminotransferase, $P T$ prothrombin time, PTT partial thromboplastin time, MMP matrix metalloproteinase, $A P R$ AST to platelet ratio index significantly lower in patients with chronic hepatitis $C$ infection relative to controls and were inversely related to the disease severity [26]. Similarly, Leroy et al. [27] found that MMP-1 serum levels decrease significantly during liver fibrosis and that MMP-1 and METAVIR fibrosis score have a negative correlation. MMP-1 was also found statistically lower in patients with grade F3 and F4 (3.6 \pm $0.8 \mu \mathrm{g} / \mathrm{mL})$ than in patients with F1 and F2 $(5.6 \pm 0.6 \mu \mathrm{g} /$ $\mathrm{mL}), p<0.001[28]$.

MMP-1 expression was observed in normal and fibrotic liver as well as a significant decrease in protein level in cirrhotic liver explants, according to previous research [29], which indicate that the decreased MMP-1 concentration may be due to increased enzyme turnover. Iimuro et al. [30] stated that transient human MMP-1 overexpression in the liver effectively attenuates proven fibrosis and induces hepatocyte proliferation and reduces the number of activated hepatic stellate cells. Collagenases MMP-1, MMP-8, and MMP-13 are essential mediators of fibrolysis because they are primarily responsible for the cleavage of fibrillar collagen [31].

In the present study, as regard histopathological evaluation by liver biopsy and different causes of liver disease and the degree of fibrosis, our results were comparable with $[24,32]$ as they found that the majority of the studied patients (80\%) showed mild disease activity. Regarding the degree of fibrosis, $45 \%$ had mild fibrosis (F1), 33.3\% had moderate fibrosis (F2), and severe fibrosis (F3) was present in $16.7 \%$ of patients. Also, the degree of fibrosis in children with $\mathrm{HCV}$ was $\mathrm{F} 1$ in $68 \%$ of cases and F2 in $28 \%$ of cases and F0 in $8 \%$. 
And most patients with Wilson disease had F4 in 70\% and F3 in 30\%. However, in patients with autoimmune hepatitis, $60 \%$ of cases were F4, 35\% was F3, and only $5 \%$ was F1 [24].

In the current study, there was a statistical difference between different degrees of fibrosis regarding APRI score and FIB4 score, as both scores increased gradually with the increasing degree of fibrosis. Our findings are consistent with a previous study that found APRI to be significantly higher in F2-3 than F0-1 ( 0.5 vs $0.3, P=$ 0.02 ), but no significant differences in FIB- 4 between F0-1 and F2-3 [33]. Similarly, Pokorska-Spiewak et al. found a significant positive association between the fibrosis stages and M-APRI, APRI, and M-FIB-4, with the mean \pm SD of APRI score $0.48 \pm 0.26$ and FIB- $40.22 \pm 0.13$ [34]. Our results were also in agreement with Elhenawy et al., who found that APRI and FIB-4 were significantly correlated with fibrosis in biliary atresia $(\mathrm{BA})(P=0.007)$ and was significantly higher in those with severe fibrosis (F4 and F5; $P=0.007$ ) and that these noninvasive serological markers, which are derived from simple routine laboratory tests, could be useful in predicting advanced fibrosis and in long-term follow-up of infants with BA, reducing the need for repeated liver biopsies [35]. Many studies have found a positive correlation between the APRI score and the severity of liver fibrosis [36, 37].

In the current study, serum MMP-1 levels did not differ according to CLD etiologies in studied patients. Also, the MMP-1 level decreased significantly as the degree of fibrosis increased, also there was a significant positive correlation between MMP-1 and albumin, hemoglobin, and platelets, as well as a significant negative correlation between MMP-1 and (ALT, AST, PT, PTT, INR, degree of fibrosis, APRI score, and FIB-4 score). Our findings were consistent with those of Ando et al. [3], who found that increased expression of MMP-1 in monocytes, KCs and HSCs was found in early NASH, but not in advanced NASH, implying an inverse association between MMP-1 levels and fibrosis progression in NASH patients and they reported that MMP-1 was involved in degrading the extracellular matrix during the recovery phase of experimental liver fibrosis in rats, MMP-1 also causes MMP-1 expressed cells to differentiate. MMP-1 is thought to play a role in NASH pathology progression. MMP-1 can help the body's response to oxidative stress by acting as a catalyst.

Liver fibrosis is a common pathologic consequence of a wide variety of chronic liver diseases, including hepatitis $B$ and $C$ virus infections, alcoholic liver disease, nonalcoholic fatty liver disease (NAFLD) especially nonalcoholic steatohepatitis (NASH), as well as primary biliary cholangitis (PBC), primary sclerosing cholangitis (PSC), and other autoimmune liver diseases (AIH). Fibrosis results from an accumulation of extracellular matrix (ECM) following the activation and proliferation of hepatic stellate cells (HSCs). Upon liver injury, excessive deposition of collagen from activated HSCs is the leading cause of liver fibrosis [38]. In chronic viral hepatitis and chronic cholestatic disorders, the fibrotic tissue is initially located around portal tracts, while in alcohol-induced liver disease it locates in pericentral and per sinusoidal areas [39]. As fibrotic liver diseases advance, disease progression from collagen bands to bridging fibrosis to frank cirrhosis occurs. In advanced stages, the liver contains approximately 6 times more ECM than normal, including collagens (I, III, and IV), fibronectin, elastin, laminin, hyaluronan, and proteoglycans. Accumulation of ECM results from both increased synthesis and decreased degradation. Decreased activity of ECM-removing MMPs is mainly due to an overexpression of their specific inhibitors (TIMPs) [40]. Collagen is degraded by matrix metalloproteinases (MMPs), which together with their inhibitor tissue. Inhibitor of metalloproteinases play key role in fibrogenesis and fibrolysis [38].

We found the best cut-off values for serum MMP-1 to detect the presence of liver fibrosis and to detect severe liver fibrosis $(\geq \mathrm{F} 3)$ were $\leq 21.3 \mathrm{ng} / \mathrm{ml}$ and $\leq 10.5$ $\mathrm{ng} / \mathrm{ml}$ with AUC was 0.972 and 1 respectively. These results were in agreement with a previous study that used MMP-1 to classify F2-F4 with an AUC of 0.70 [41]. Another study found that the MMP-1 AUC was 0.98 for distinguishing patients with cirrhosis from healthy individuals with $98 \%$ sensitivity and $97 \%$ efficiency and 0.78 for distinguishing patients with cirrhosis from non-cirrhotic patients with $71 \%$ sensitivity and $73 \%$ efficiency [42], while the area under the curve was 0.82 to testing ability to identify mild fibrosis stages (METAVIR F0, F1 vs F2, F3, F4) [27].

The main limitation of this study was the inability to take serial samples to follow-up the tested marker along with disease course, progression, and response to therapy.

\section{Conclusion}

Matrix metalloproteinase-1 may be a promising noninvasive biomarker in children with chronic liver disease reflecting the degree of liver fibrosis. To confirm these findings and assess the function of matrix metalloproteinase- 1 in the follow-up of children with chronic liver fibrosis and their response to therapy, larger-scale studies may be needed.

\section{Abbreviations}

CLD: Chronic liver diseases; MMP-1: Matrix metalloproteinase-1; ECM: Extracellular matrix; ELISA: Enzyme-linked immunosorbent assay; FI: Degree of fibrosis; 
HAl: Histological activity index; APRI: Aspartate aminotransferase to platelet ratio index; FIB-4: Fibrosis-4 score; HSCs: Hepatic stellate cells.

\section{Acknowledgements}

Authors would like to thank all children and their parents who participated in this study.

\section{Authors' contributions}

$\mathrm{O}$ B: Contributed to the design and implementation of the research, aided in choosing the patients and helped shape the research, supervised the findings of this work, discussed the results, read and approved the final manuscript. $M E$ : Contributed to the design and implementation of the research, aided in choosing the patients and helped shape the research, supervised the findings of this work, discussed the results, read and approved the final manuscript. A $\mathrm{M}$ : Contributed to the design and implementation of the research, aided in choosing the patients, performed the laboratory work and helped shape the research, supervised the findings of this work, discussed the results, read and approved the final manuscript. G E: Contributed to the design and implementation of the research, aided in choosing the patients and helped shape the research, supervised the findings of this work, discussed the results, read and approved the final manuscript. "All authors have read and approved the manuscript".

\section{Funding}

No funding -no grants.

\section{Availability of data and materials}

All data and materials are available.

\section{Declarations}

\section{Ethics approval and consent to participate}

The study was performed according to the ethical guidelines of the 1975 Declaration of Helsinki. The current study was approved by the Medical Research Ethical Committee of the Faculty of Medicine, Benha University. All subjects were informed about the procedures and the aim of the study and informed written consent was obtained from the parents or caregivers of enrolled children. The committee's reference number is not applicable and/not available.

\section{Consent for publication}

Not applicable

\section{Competing interests}

The authors declare that they have no competing interests.

\section{Author details}

'Pediatrics Department, Faculty of Medicine, Benha University, Qualiopia, Benha, Egypt. ${ }^{2}$ Clinical and Chemical Pathology Department, Faculty of Medicine, Benha University, Benha, Egypt. ${ }^{3}$ Faculty of Medicine, Benha University, Benha, Egypt.

Received: 20 April 2021 Accepted: 18 September 2021 Published online: 30 September 2021

\section{References}

1. Abou-Taleb A, Ahmed A, El-Hennawy A (2019) Pediatric chronic liver diseases: a clinicopathological study from a tertiary care center. Int J Pediatr 7(4):9305-9315

2. Behera A, Murmu M (2018) A study on clinico-etiological profile of chronic liver disease in children between 1 year to 14 years of age. Int J Pediatr Res 5:31-36

3. Ando W, Yokomori H, Tsutsui N, Yamanouchi E, Suzuki Y, Oda M et al (2018) Serum matrix metalloproteinase-1 level represents disease activity as opposed to fibrosis in patients with histologically proven nonalcoholic steatohepatitis. Clin Mol Hepatol 24(1):61

4. Li C, Li R, Zhang W (2018) Progress in non-invasive detection of liver fibrosis. Cancer Biol Med 15(2):124-136
5. Geervliet E, Bansal R (2020) Matrix metalloproteinases as potential biomarkers and therapeutic targets in liver diseases. Cells. 9(5):1212

6. Ma Y, Brás LEDC, Toba H, Iyer RP, Hall ME, Winniford MD et al (2014) Myofibroblasts and the extracellular matrix network in post-myocardial infarction cardiac remodeling. Pflugers Arch 466:1113-1127

7. limuro Y, Brenner DA (2007) Matrix metalloproteinase gene delivery for liver fibrosis. Pharm Res 25:249-258

8. Fields GB (2013) Interstitial collagen catabolism. J Biol Chem 288:8785-8793

9. Vergani GM, Vergani D (2002) Autoimmune liver disease. In Symposium on Hepatology. Ind J Paediatr 69(1):93-98

10. England JM, Rowan RM, vanAssendelft OW, Coulter WH, Groner W, Jones AR et al (1984) Protocol for evaluation of automated blood cell counters. International Committee for Standardization in Haematology (ICSH). Clin Lab Haematol 6:69-84

11. Lewis SM, Barbara J, Bain IB, Dacie JV, John V (2006) Dacie. Dacie and Lewis Practical Haematology. Churchill Livingstone/Elsevier, Philadelphia

12. Tietz (2005) Textbook of Clinical Chemistery and Molecular Diagnostics, 4th ed. In: Burtis CA, Ashwood ER, Bruns DE, eds. Elsevier Saunders, St. Louis

13. Pagana KD, Pagana TJ (2011) Mosby's diagnostic and laboratory test reference, 10th edn. Mosby, Inc., Saint Louis

14. Roggenbuck D, Hiemann R, Bogdanos D, Reinhold D, Conrad K (2013) Standardization of automated interpretation of immunofluorescence tests. Clin Chim Acta 421:168-169

15. National Committee for Clinical Laboratory Standards. Proposed guidelines: specifications for immunological testing for infectious disease. Villanova,PA: National Committee for Clinical Laboratory Standards,1991;11(19).(NCCLS document I/LA 18-P).

16. Nomura F, Itoga S (2002) Molecular diagnosis of hepatitis B virus and hepatitis $C$ virus infection. Rinsho Byori 123:31-36

17. Wintrobe's Clinical Hematology (2009) 12th ed. In: Greer J, Foerster J, Rodgers G, Paraskevas F, Glader B, Arber D, Means R, eds. Lippincott Williams \& Wilkins, Philadelphia. Pp 1430-1431, 1436-1437

18. Engvall E, Perlmann P, Enzyme -linked immunosorbent assay (ELISA) (1971) Quantitative assay of immunoglobulin G. Immunochemistery 8:871-874

19. Fridman R, Fuerst TR, Bird RE et al (1992) Domain structure of human 72-kDa gelatinase/type IV collagenase. Characterization of proteolytic activity and identification of the tissue inhibitor of metalloproteinase-2 (TIMP-2) binding regions. J Biol Chem 267:15398-15405

20. Wai CT, Greenson JK, Fontana RJ, Kalbfleisch JD, Marrero JA, Conjeevaram HS, Lok AS (2003) A simple noninvasive index can predict both significant fibrosis and cirrhosis in patients with chronic hepatitis $C$. Hepatology. 38(2):518-526

21. Sterling RK, Lissen E, Clumeck N, Sola R, Correa MC, Montaner J et al (2006) Development of a simple noninvasive index to predict significant fibrosis in patients with HIV/HCV coinfection. Hepatology 43(6):1317-1325

22. Bedossa P, Poynard T (1996) An algorithm for the grading of activity in chronic hepatitis C. The METAVIR Cooperative Study Group. Hepatology 24:289-293

23. Duarte S, Baber J, Fujii T, Coito AJ (2015) Matrix metalloproteinases in liver injury, repair and fibrosis. Matrix Biol 44-46:147-156

24. Behairy BE-S, Sira MM, Zalata KR, Salama E-SE, Abd-Allah MA (2016) Transient elastography compared to liver biopsy and morphometry for predicting fibrosis in pediatric chronic liver disease: does etiology matter? World I Gastroenterol 22:4238

25. Dar GA, Malik MI, Ganie FA, Jan H, Abdullah T, Dar MI, Dar MA (2014) Chronic liver diseases in children: clinical spectrum and etiology. $\mathrm{Br}$ Biomed Bull 2:406-411

26. Murawaki Y, Ikuta Y, Idobe Y, Kawasaki H (2002) Serum matrix metalloproteinase-1 in patients with chronic viral hepatitis. J Gastroenterol Hepatol 14:138-145

27. Leroy V, Monier F, Bottari S, Trocme C, Sturm N, Hilleret MN et al (2004) Circulating matrix metalloproteinases 1, 2, 9 and their inhibitors TIMP-1 and TIMP-2 as serum markers of liver fibrosis in patients with chronic hepatitis C: comparison with PIIINP and hyaluronic acid. Am J Gastroenterol 99(2):271-279 
28. Attallah AM, Albannan MS, El-Deen MS, Farid K, Khedr FM, Attallah KA et al (2020) Diagnostic role of collagen-III and matrix metalloproteinase-1 for early detection of hepatocellular carcinoma. Br J Biomed Sci 77(2):58-63

29. Lichtinghagen R, Breitenstein K, Arndt B, Kühbacher T, Böker KH (1998) Comparison of matrix metalloproteinase expression in normal and cirrhotic human liver. Virchows Arch 432(2):153-158

30. limuro Y, Nishio T, Morimoto T, Nitta T, Stefanovic B, Choi SK et al (2003) Delivery of matrix metalloproteinase-1 attenuates established liver fibrosis in the rat. Gastroenterology. 124(2):445-458

31. Voutilainen SH, Kosola SK, Tervahartiala TI, Sorsa TA, Jalanko HJ, Pakarinen MP (2017) Liver and serum expression of matrix metalloproteinases in asymptomatic pediatric liver transplant recipients. Transpl Int 30:124-133

32. Behairy OG, Al Rawhaa A, Mansour Al, Mohamed KI (2020) Association between vitamin $D$ status and depression in children with chronic liver disease. Egypt Liver J10:1-8

33. Mercedes R, Brown J, Minard C, Tsai CM, Devaraj S, Munden M et al (2020) A liver biopsy validation pilot study of shear wave elastography, APRI, FIB4 , and novel serum biomarkers for liver fibrosis staging in children with chronic viral hepatitis. Glob Pediatr Health 7:2333794X20938931

34. Pokorska-Śpiewak M, Kowalik-Mikołajewska B, Aniszewska M, Pluta M, Marczyńska M (2017) Clinical usefulness of new noninvasive serum biomarkers for the assessment of liver fibrosis and steatosis in children with chronic hepatitis C. Clin Exp Hepatol 3(4):198-202

35. Elhenawy IA, Ghanem HS, Sultan MM, Sira MM (2017) Utility of noninvasive serum biomarkers of liver fibrosis in infants with biliary atresia. Adv Res Gastroentero Hepatol 3(2):555607
36. Kim SY, Seok JY, Han SJ, Koh H (2010) Assessment of liver fibrosis and cirrhosis by aspartate amino transferase-to-platelet ratio index in children with biliary atresia. J Pediatr Gastroenterol Nutr 51(2):198-202

37. Papadopoulos N, Vasileiadi S, Papavdi M, Sveroni E, Antonakaki P, Dellaporta E et al (2019) Liver fibrosis staging with combination of APRI and FIB-4 scoring systems in chronic hepatitis $C$ as an alternative to transient elastography. Ann Gastroenterol 32(5):498-503

38. Robert S, Gicquel T, Bodin A, Lagente V, Boichot E (2016) Characterization of the MMP/TIMP imbalance and collagen production induced by IL-1 $\beta$ or TNF-a release from human hepatic stellate cells. PLoS One 11(4):e0153118

39. Pinzani M (1992) Liver fibrosis. Springer Semin Immunopathol 21:475-490

40. Arthur MJ (2000) Fibrogenesis II. Metalloproteinases and their inhibitors in liver fibrosis. Am J Physiol Gastrointest Liver Physiol 279:245-249

41. Attallah AM, El-Far M, Malak CAA, Omran MM, Farid K, Hussien MA et al (2015) Fibro-check: a combination of direct and indirect markers for liver fibrosis staging in chronic hepatitis $C$ patients. Ann Hepatol 14(2):225-233

42. Attallah AM, Badr El-Din NK, Omran MM, Farid K, El-Wahab AH, El-Bendary $M$ et al (2011) Assessment of matrix metalloproteinase-1 for marking liver cirrhosis in chronic hepatitis C patients. Egypt J Immunol 18(1):33-42

\section{Publisher's Note}

Springer Nature remains neutral with regard to jurisdictional claims in published maps and institutional affiliations.

\section{Submit your manuscript to a SpringerOpen ${ }^{\circ}$ journal and benefit from:}

- Convenient online submission

- Rigorous peer review

- Open access: articles freely available online

- High visibility within the field

- Retaining the copyright to your article

Submit your next manuscript at springeropen.com 